\title{
Fan Device
}

National Cancer Institute

\section{Source}

National Cancer Institute. Fan Device. NCI Thesaurus. Code C49947.

A device designed to create an air current through the rotation of a planar surface. 